\title{
Asian Students' Citizenship Values: Exploring Theory by Reviewing Secondary Data Analysis
}

\author{
Kerry J. Kennedy
}

\begin{abstract}
It has been argued that "Asian values" in general and Asian citizenship values in particular are distinctive to the region. A range of theoretical literature has advanced this view. Scholars have referred to an "Asian modernity," reflecting regional citizenship values across time and borders. This departs from the largely Western idea of a set of universal democratic values that are characteristic across countries and has important implications for citizenship education. This chapter summarizes empirical analyses that have used IEA International Civic and Citizenship Education Study (ICCS) 2009 data to explore "Asian" citizenship values, their extent, and their meaning. The results suggest that diversity rather than uniformity characterizes students' citizenship values in five Asian societies. Within and across these societies there are varying levels of endorsement of citizenship values (including traditional values), and support for civic engagement. This chapter highlights several ways of thinking about Asian citizenship values and suggests an ongoing research agenda to address the diversity that characterizes the region.
\end{abstract}

\section{Introduction}

Secondary analysis of data is a powerful tool for informing theoretical perspectives (Smith 2008; Hakim 2013). Yet, as Bauer (2009) pointed out, if data is to be linked to theory it is important to specify the type of theory. He identifies three types of theory that are broadly sociological in nature: "social theory" that is concerned with core concepts that explain how society works; "middle range theories" that focus on specific themes that characterize some aspect of society; and "theories of society" that try to encapsulate some general aspect of an entire society (p. 10). Citizenship values reflect this society-wide view since they are often portrayed almost as a world view. The idea of "liberal democratic values," for example, reflects a set of citizenship values that are expected to characterize a wide range of democratic societies.

As helpful as this categorization is, it can break down when applied to a region. For example, using a term such as "Asian values" implies that within multiple societies there is a commonality in world views and perspectives that can be considered distinctive. Searching for "Asian values" across societies assumes that there are "grand" theories of society that transcend geographies, histories, and cultures. As appealing as this idea might be, there is considerable skepticism about "grand theory" in social science research (Lyotard 1984).

Chen (2005) has proposed, however, that research focused on "Asia as method" can overcome this problem (p. 141). Such research "ceases to look at Asia as object of analysis" (Chen 2005, p.141) but rather as a point of reference, and importantly as a means of "inter-referencing." Koh (2018) urges scholars studying Asia to take an "inter-referencing perspective" where Western values are not the reference point for understanding Asian contexts. Rather, as Chen (2005) explained:

"... mediating through the horizon of 'Asia' as an imaginary anchoring point, societies in Asia could begin to mutually see the existence of one another and become one another's reference points" (p. 140).

Inter-referencing is the approach taken here to look comparatively at Korea, Taiwan, Hong Kong, Indonesia, and Thailand-participating countries in the International Civic and Citizenship Education Study (ICCS) 2009 (Fraillon et al. 2012). The first sections below summarize research studies examining the extent to which young people endorsed a set of common "Asian values."

Kerry J. Kennedy, Department of Curriculum and Instruction, The Education University of Hong Kong, Hong Kong email: kerryk@eduhk.hk

(C) IEA International Association for the Evaluation of Educational Achievement 2021 
The chapter then explores the associations between those values and specific forms of civic action. Finally, there is an examination of theoretical implications and suggestions for future research directions.

What follows acknowledges multiple sources that influence Asian adolescents' citizenship values. Indigenous understandings of citizenship are identified as well as the influence of "foreign" or external values. These two sources inevitably interact in the increasingly globalized world of Asia's young people.

\section{Indigenous Views of Citizenship Values-An Asian Journey}

A distinction between the so called "Asian values debate" and genuine attempts to discern common values across Asian societies is helpful. The former was motivated by regional politicians such as Singapore's Lee Kuan Yew and Malaysia's Mahathir Mohamad to shield their respective societies from the onslaught of globalization, and from foreign interference. Hard work, collectivism, and respect for authority were heralded as the values that drove economic expansion in much of Asia in the 1990s and these were often posed against what were seen as more permissive values of many Western nations (Kennedy 2004).

In addition to the politicians' public debate referred to above, another debate took place out of the glare of media headlines. It was largely a debate from a neo-Confucian perspective, but often with an eye on the political debate concerning "Asian values" (Tu 1996; Shin 2012). Lee (2004 a, b) took up these issues and applied them to citizenship education. While his analyses focused on what might be called Confucian values, these values also had resonance in Islamic and Buddhist societies. Lee's (2004a) summary contrasts Western with local regional citizenship values:

"With this background in mind, it has become easy to understand several features of citizenship education in the East. First, rather than talking about politics, citizenship education in the East talks about morality. 'Civics' always goes with 'morals' in the East; thus, civic and moral education is a term more common than civics education or citizenship education in Asian countries. Second, many Asian countries tend to focus on the development of individuality (as far as the self is concerned) and relations (as far as society is concerned) in citizenship education" (p.32).

The "individuality" referred to is not coincident with Western notions of individualism. Individuality, in a Confucian context, is more about the importance of self-cultivation-being the best person you can be. The rationale for self-cultivation is not self-aggrandizement (as in Western versions of individualism), it is about relationships-serving family, society, and the nation. This led Lee (2004a) to observe somewhat provocatively, "to Asian citizens, it does not matter who rules and in what way the country is ruled, as far as they are in a situation where they can live their lives, maintain their relationships, and pursue their individuality... then they will live with whoever the ruler is, unless the situation becomes intolerable" (p.31).

This summary does not do justice to the rich discourse concerning values in the Asian region, but it does suggest its contours. This discussion assumed central importance, however, when the International Association for the Evaluation of Educational Achievement (IEA) decided to include an Asian student questionnaire (ASQ) in addition to the main student questionnaire in ICCS 2009, Fraillon et al. (2011) commented that:

"The ICCS Asian regional module was a unique attempt to capture data using a perspective on civics and citizenship that was different to that of the core ICCS international instruments. This perspective, which places an emphasis on personal morality and character as integral to citizenship, was agreed to be relevant across the five ICCS Asian countries despite their cultural and educational diversity" (p. 5).

This statement legitimized conceptions of citizenship that differed in some respects from those supported in liberal democracies. This distinctiveness can be taken further. The notion of "citizen," 
for example, is a construct derived from the Western experience. There is, for example, no simple Chinese translation for "citizen" (Guo 2014) and the possibilities are laden with political implications. Thus, the term, "citizenship education" is rarely used in China because of the multiple meanings it can convey (Li 2015). Local contexts, therefore, are important sources for constructing meaning around terms and concepts imported from Western citizenship discourse. Given the range of Asian societies participating in ICCS 2009-Korea, Taiwan, Hong Kong, Indonesia, and Thailand-the significance of local contexts needs to be appreciated.

The appreciation of context is the starting point for this chapter. Asian citizenship values represent historical, cultural, social, and political constructions from diverse societies within a single geographical region. These traditional values represent regional traditions that continue to influence young people along with the liberal democratic values that were reflected in the ICCS main survey (Schulz et al. 2010). Yet to some extent traditional values are independent, representing regional traditions that continue to influence young people. An important issue is how such values were identified and defined.

For ICCS 2009, traditional values were identified during several meetings that included researchers from the participating Asian societies and ICCS 2009 managers. Specific items to reflect the values were agreed upon and formed scales for the ASQ. Lin and Liu (2011) describe this process, Kennedy (2011) provided an initial analysis and discussion, and Fraillon et al. (2012) reported the results.

\section{Traditional Values, Conceptions of "the Good Citizen," and Civic Action: What Can be Learned About Asian Students' Conceptions of Citizenship Responsibilities?}

The following questions will be explored with respect to the traditional values referred to above:

- How did students from different societies within the region respond to questions and how can their responses be interpreted?

- Are traditional values related to the way Asian students understand what it means to be "a good citizen?" How much agreement is there about what "a good citizen" means?

- Is there an association between students holding traditional values and their preferred forms of civic action?

\section{Student Responses and Some Interpretations}

First, there was significant agreement on values. A "sense of Asian identity," "the need to preserve traditional culture," "the need for politicians to demonstrate a strong sense of morality," and "a shared understanding of the qualities of 'good citizens"' received relatively high levels of endorsement, suggesting these were important shared values. There were other values that were endorsed more moderately. These were supportive of social conventions such as "respect for authority," the "need to maintain social harmony," and "authoritarian or paternalistic forms of government." In addition, there was moderate to strong support for the integrity of each country's legal system.

Second, differences between countries were also found in attitudes "to corruption in the public service," "the use of 'connections' to gain political office," "acceptance of undemocratic government," and "obedience towards authority." Students from Korea, Taiwan, and Hong Kong gave these values generally negative endorsements. Students from Indonesia and Thailand were moderately positive. What do these patterns of endorsement on the ASQ scales mean?

The overall picture is of young people who are quite conservative in their values, with some groups of students more conservative than others. They tend to subscribe to values related to obedience, authority, morality, harmony, tradition, and a sense of Asian identity. Westheimer 
and Kahne's (2004, p. 242) typology of citizenships does not fit this data: these young Asian students are certainly not "justice-oriented citizens" and they cannot accurately be referred to as "personally responsible citizens" since their commitments are more broadly social than personal. As Tu Weiming, the Confucian scholar, has pointed out "in the Western and the non-Western worlds, the projected transition from tradition to modernity never occurred. Traditions continue in modernity" (Tu 2000, p. 198). Thus, we see substantial numbers of "tradition-oriented citizens" embedded in modern nations but anchored to social and cultural traditions from which these nations have emerged. What is more, specific national contexts are associated with the extent to which students endorsed particular values.

These conclusions, drawn from the analysis of descriptive statistics, are a starting point for understanding Asian student's citizenship values. Yet these students are in modern nations subject to intensive processes of globalization and interactions with alternative value systems. Inglehart and Baker (2000, p. 49) argue that values from traditional societies may be retained even when new sets of values enter society. These multiple influences contribute to the development of their citizenship values. The following section will consider how these multiple influences are reflected in Asian students' conceptions of "the good citizen."

\section{To What Extent is There Agreement on Traditional Values and Conceptions of the "Good Citizen"?}

All societies, democratic and authoritarian, Western and Eastern, old and new, are interested in nurturing "good citizens" to provide the basis for a society's legitimacy and priorities. In the ASQ, students were asked the extent to which they would endorse statements such as "a person who obeys the law but does not behave morally is not a good citizen," "one can only be a good citizen if one is a good moral person," and "having good morality is more important than having good knowledge for one to be a good citizen." Some items were strongly endorsed by students from across the region. Kuang and Kennedy (2014) tested the association between traditional values, such as those described above, and liberal democratic values. This involved exploring the association between students' perceptions of the moral qualities of a "good citizen," their democratic values along with their attitudes to traditional culture and to the behaviors of "good citizens" in both conventional and social-movement terms.

The results suggested that students' endorsement of "attitudes to the moral quality of citizens" was a weak predictor of both "attitudes to conventional citizenship" as well as "attitudes toward social movement citizenship" as defined internationally. This suggested that these traditional values had something in common with Western citizenship values. In addition, "attitudes to traditional culture" had a moderate association (except in Indonesia) with "attitudes to conventional citizenship" and with "attitudes to social movement citizenship."

What do these results mean? Context seems to influence the extent to which these traditional values are adopted. At the same time, traditional values do not appear to be antithetical to liberal democratic values and behaviors - students with strong views about preserving traditional culture are likely to be supportive of engaging in both conventional citizenship (like voting) and social movement citizenship (such as participation in the community). This suggests the possibility of new frameworks for understanding citizenship values and their expression in Asian contexts. Other researchers have advanced similar ideas.

Knowles (2015), for example, using the Korean sample of students from ICCS 2009, explored traditional and democratic values. He developed two scales from the ASQ data. The first scale, Asian Civic Values, included these items: "Government should take care of its people," "Political leaders should be role models of morality," "A person who obeys the law but is not a moral person is not a good citizen," "One can only be a good citizen if one is a moral person," and "Classmates should not argue with each other to maintain social harmony." The second scale was Obedience to 
Authority and included: "Even if you have a different opinion, you should always follow the advice of elders when making important decisions," "Even if you have a different opinion, you should always follow the advice of the people with the highest status position when making important decisions," "Even if you have a different opinion, you should always obey your teachers," "Even if you have a different opinion, you should always obey your parents." The results of Knowles' analysis provided insights into the way Korean students conceptualized traditional values and key influences on these values.

Having identified that traditional values had two dimensions, Knowles (2015) sought to establish their statistical associations with several aspects of democratic citizenship as defined for the ICCS cross national samples as a whole (including individual measures such as civic knowledge, democratic values, civic efficacy). He found that Asian Civic Values was positively correlated to Democratic Citizenship while Obedience to Authority was negatively correlated. He suggested that it was no longer reasonable to talk about traditional Asian values as a single construct. There were also important group differences. Males and lower SES (socioeconomic status) students endorsed "Support for undemocratic government" more strongly than females and higher SES students.

These results highlighted not only the multidimensional nature of traditional values but also the nature of those values. One interpretation of Asian Civic Values is that they represent passive characteristics with a distinct moral dimension. These characteristics, however, appear to be consistent with holding democratic values concerning respect for individuals and tolerance for difference. The other key finding from Knowles' analysis was the suggestion that Korean students hold traditional values and the democratic values associated with European mindsets in some kind of balance. This supported the views of Tu (2000) and Inglehart and Baker (2000) referred to earlier and the empirical results of Kennedy et al. (2013).

Other studies have used samples from ICCS 2009 students in several societies. One study focussed on what were called "alienated and disaffected students" in Europe, Asia, and South America and their citizenship values (Kuang 2016). She investigated civic knowledge, skills, and attitudes and their association with traditional values. For the Asian component she drew on ASQ samples from Taiwan, Hong Kong, Korea, Indonesia, and Thailand.

Using latent profile analysis (LPA) and a range of citizenship variables, she identified three profile groups of students within the region. The first she labelled "Outsiders" because on most variables such as civic beliefs, participation experiences, holding norms supporting conventional citizenship and social movement citizenship, and sense of efficacy, their scores were uniformly low. These students made up $12 \%$ of the sample across the region. The second group she named the "Moderates" because their scores on these variables were mostly average. These students made up $86 \%$ of the regional sample. The third group was named "Active Participators" because their scores were mostly above the mean for all variables. They made up $2 \%$ of the sample across the region. Thus, this person-centred methodology highlighted the diversity of citizenship values across the region, although the largest group by far showed moderate engagement.

There were also differences within each of the societies. In Korea, Outsiders made up 24\% of the national cohort while the percentages were 14\% in Hong Kong, 10\% in Taiwan, 9\% in Thailand, and $4 \%$ Indonesia. The existence of students who could be classified as Outsiders in every society points to some commonality across societies irrespective of culture and political system. They are largely neglected in citizenship research and citizenship education. Outsiders were not represented to the same extent in all societies but were more prevalent in democracies such as Korea than Indonesia.

Kuang (2016) also found that boys were more likely to be Outsiders than girls and that students with lower expectations for further education and fewer books in the home were more likely to be Outsiders. These results were consistent with Knowles' (2015) findings in Korea. In addition, 
the more highly students scored on values and behaviors such as "interest in politics," "attitudes towards the nation," "discussion of politics," "community participation," "valuing of school participation" and the "perceived openness of classroom climate," the less likely they were to be Outsiders and the more likely they were to be Active Participators. These results add weight to the idea that Asian students display a diversity of civic values. A small proportion appears to have confidence in civic values (the Active Participators) while others show much less confidence (the Outsiders). Those in the majority (the Moderates), however, were positive, having endorsed all values at an average level.

When considering citizenship values and civic participation, researchers often focus on traditional forms of engagement (voting, volunteering activities, responding to environmental problems, legal protests). Kuang (2016), however, found that the Outsiders were more likely than the other groups to see themselves in the future engaging in illegal protest. Students' endorsement of illegal protest was also associated with their endorsement of what were called negative traditional values (for example, "attitudes condoning corruption in the public service" and "the use of 'connections' to gain political office"). On the other hand, endorsement of positive traditional values predicted support for conventional civic engagement. The issue of civic action is discussed in the next section, especially in relation to illegal protest.

\section{Asian Students' Civic Action-To Protest or Not to Protest?}

Extreme forms of civic action have characterized a number of Asian societies in the 2000s: The Red Shirts in Thailand, the anti-Park forces in Korea, the religious protestors in Indonesia, the Umbrella Movement in Hong Kong, and the Sunflower Movement in Taiwan. Some research on these groups has recently appeared (Chan et al. 2017). Little is known, however, about how this student radicalism emerged, especially given the extent to which the generation of students tested in ICCS 2009 demonstrated commitments to traditional values.

Asian students, like many elsewhere, navigate between traditional and more radical citizenship values. Zhu et al. (2018), for example, were interested in the associations between out of school participation experiences, political interest, internal political efficacy (confidence that you know enough to participate in politics), and citizenship self-efficacy (a belief that by being involved in specific political activities you make a difference) with Asian students' future intentions to participate in legal protest.

"Community participation," as part of school civic education, was the only civic experience to be associated directly with "expected participation in legal protest" in Hong Kong, Indonesia, Korea, and Thailand. The statistical effects, while significant, were weak. On the other hand, the associations of student self-efficacy with "expected participation in legal protest" were moderate and significant across all these societies. There was some evidence that civic experience has different effects for students who hold different patterns of attitudes. For example, Zhu et al. (2018) showed that students with high levels of political interest seemed more likely to benefit from political discussion than students who displayed less interest. What do these results mean for our understanding of Asian students' citizenship values?

These results raise a number of issues. Perhaps most importantly, the study showed that legal protest, as a form of future civic engagement was not rejected by Asian adolescents in 2009. For many students a moderate endorsement of expected participation in legal protest coexisted with holding traditional values. This reinforces the argument that democratic and traditional values are not necessarily antithetical. The connection with expected participation in legal protest, however, is not the same across the region. The extent to which a student from South East Asia (Thailand and Indonesia) was likely to be influenced by experiences of political discussion and by possessing political interest and internal political efficacy was modest. They differed from their peers from East Asia where these associations seemed to be stronger. Thus, while 
the possibility of protest action is common across the region, the reasons for taking such action may be associated with different factors in the different contexts.

On several characteristics Korean students stood out perhaps because they seemed to be the least traditional and most committed to democratic values. As Zhu et al. (2018, p. 13) pointed out: "geographic and cultural differences should be considered when understanding expected participation in legal protest. Moreover, these diversities need to be further explored." Political differences could also be included as part of these broad social contexts. This is a topic for qualitative research paying close attention to the cultural, political, and social contexts in which students live and develop citizenship values.

Another topic of interest was illegal protest, especially given the student movements in Hong Kong and Taiwan beginning in 2014. Chow's (2013) study, using ICCS 2009 data, found that illegal protest was considered a future civic engagement option by a relatively small proportion of adolescents across the region. Similarly, Wang (2019), using a survey based on ICCS 2009, found with samples of students from Mainland China that around 10\% endorsed illegal protest positively as a future option for themselves.

Kuang and Kennedy (2018) explored reasons for adolescents to consider illegal protests as a potential form of future civic engagement. They focused on Hong Kong students and their attitudes to future engagement in both legal and illegal protest activities as measured by ICCS 2009. Using a person-centred approach, they identified two groups. The "Rationals," who scored above the mean on civic knowledge, had, on average, high scores on self-efficacy, showed positive attitudes to equality, and made up around 65\% of the sample. The "Radicals," on the other hand, had "lower civic knowledge, lower civic efficacy, and a more negative attitude toward traditional citizenship values such as personal morality, social cohesion, and traditional culture" (p.10). Yet there were also significant differences in the two groups' endorsement of the three items that made up the illegal protest scale. The Rationals in Hong Kong were much less likely to endorse illegal protest items than the Radicals, suggesting this was unlikely to be a civic activity in which they would engage. The Radicals, were less likely than the Rationals to endorse the legal protest items, but their level of endorsement suggested it was an expected form of civic engagement they would consider.

As always with this type of research, an important issue is whether the profile groups identified in the person-centred analysis are valid. Can they be associated with other citizenship values in addition to illegal protest? A clear result was that the two groups differed significantly in what might be called their "civic capacity" or "civic resources:" the Radicals had lower civic knowledge scores, less positive attitudes to equality (gender, ethnic, and immigrant), traditional culture and conventional and social movement citizenship, and more positive attitudes toward exploiting familial connections in elections. What this suggested was that opting for illegal protest as a form of civic engagement might reflect a lack of civic capacity or resources.

As for the composition of these groups, males were more likely to be Radicals, as were students from low SES backgrounds as well as students whose parents showed little interest in discussing social and political issues. Positive citizenship values were associated with lower likelihood of membership in the Radicals while support for negative traditional values (for example, "condoning corruption") was associated with higher likelihood of membership of the Radicals. These results showed that even within a single Asian society there was considerable diversity of attitudes towards future civic engagement. But how generalizable are these findings to other contexts?

A follow up analysis (Li et al. 2016) comparing Hong Kong and Taiwanese students' attitudes to illegal protest found similar results. For example, those students supporting illegal protest had lower knowledge scores. Future radical civic action was part of the thinking of a minority of Hong Kong and Taiwanese students. There is no way of knowing whether these 14-year-olds in 
2009 became involved in the local student movements in these two societies beginning in 2014. More attention is needed to the trajectories of young people's thinking and action associated with various forms civic engagement and protest. While the quantitative studies reviewed above have been helpful, more qualitative data on the citizenship values of radical students is needed. How qualitative and quantitative methods contribute to understanding of civic engagement will be discussed in the next section.

\section{Conclusions and Future Directions}

\section{De-emphasize Concern About Distinctive "Asian Citizenship Values"}

Most Asian students' citizenship values are multidimensional. They include so-called traditional values as assessed in the ASQ, but also a variety of other democratic values related to political institutions, equality, and different forms of civic engagement. For some students, democratic values and traditional values can be held in balance. Yet across the region there is variation in the average endorsement of these values, and there is variation within societies as well as across societies. Citizenship values in Asian societies, therefore, appear to reflect not so much a single set of regional specific values as what Stasiulis (2004), in a European context, referred to as a "hybrid citizenship." She saw such hybridity resulting from increased mobility and migration under the influence of globalization. In Asian contexts, however, hybrid forms of citizenship appear to have emerged when new forms of governance encountered older cultural systems. It may be more accurate to discuss hybrid identities, since many Asian young people balance their traditional with democratic orientations (or traditional with undemocratic orientations). They are anchored to an older set of cultural assumptions and practices, but this does not prevent many of them from embracing democratic values.

It is debatable whether Lee (2004a) was accurate in declaring that many Asians do not care as much about the form of governance as whether leaders maintain a positive approach to citizen welfare and values. Demonstrations in Hong Kong, Korea, and Taiwan from 2014 onwards, for example, have shown that substantial numbers of their citizens care very much about democratic values to the point where they openly question and protest against leaders. In these cases, citizens may be protesting what they see as poor leadership for which there is warrant from both traditional and democratic values.

Another important conclusion is that democratic values, while important for the Asian students surveyed in ICCS 2009, compete with other value systems. Liberal democratic governments may be in place in Korea, Taiwan, and Indonesia. It appears that substantial numbers of students in several of these countries have democratic aspirations. Democratic values, however, compete with Confucian values in East Asian societies, Islamic values in Indonesia, and Buddhist values in Thailand. The everyday experiences of many Asian students are steeped in religious and cultural values as well as secular values resulting from globalization together with democratic values. It is interesting to reflect on what daily life must be like for these young people as they negotiate these multiple value systems and whether similar contexts challenge young people in other societies.

In addition, for students in Hong Kong and Thailand, the actions of authoritarian governments are never far from public observation. Yet based on the results discussed here, democracy is clearly important for these students. Democracy represents, however, but one value system in a region characterized by diverse values and a history of domination by successive conquerors bringing new values. It is this mélange and its potential to shape the region's citizens that needs to be understood. It is hybridity that helps to explain Asian students' citizenship values, a hybridity that operates differently in different contexts and that seems to be associated with demographic characteristics such as gender and socioeconomic position within specific countries. 
While it is possible to describe how many Asian students select and act on their citizenship values, it is more difficult to understand their specific motivations. Civic knowledge is a strong predictor of positive citizenship values. It appears that many students with negative traditional values also have negative attitudes to democratic values such as voting, equality, and participation. Yet the mechanisms are unclear. Political efficacy needs to be better understood in Asian contexts, especially its links with Western individualism. The interplay between Asian value systems and other systems, and how together these influence students' civic decision making are important areas for research.

\section{Examine "Active Citizenship" Asian Style}

Participation is a value for many Asian students and conventional participation is the preferred mode. At the same time some individuals are prepared to engage in illegal as well as legal forms of protest. In an important sense, the use of protest runs counter to traditional values concerned with obedience, harmony, and respect. Yet it is quite clear, given the "red" and "yellow" shirts in Thailand, the pro-Islamic protests in Indonesia, the "Umbrella" and "Sunflower" student movements in Hong Kong and Taiwan respectively, and the anti-Park protests in Korea, that some issues in these societies have the potential to prompt protest. For adults, at least, protest appears to be the only way to show a diminution of trust in the benevolence of political leaders. An important question: at what point, in a developmental sense, do most young people consider practicing these less conventional forms of civic engagement? It is clear from the studies discussed here that these less conventional forms of action are already part of potential civic repertoires for some adolescents. Yet what motivates actual civic action for young people is an important issue for future research.

The majority of studies discussed above were conducted with samples of students who experienced, in one way or another, a democratic political environment (or at least a substantial amount of democratic discourse, for example, in Hong Kong). Wang's (2019) study included students from Mainland China, governed by a single party regime with no commitment to liberal democratic values. The students in her study endorsed participatory activity, but primarily as a regime supporting activity. This is in contrast to the democratic view that allows for and supports regime challenging activities. The way participation is both encouraged and enacted in authoritarian societies, the kind of incentives that exist, and what citizens hope to achieve need further study.

Another important issue is the role of civic education. Reichert and Torney-Purta (2019), among others, have found that Asian teachers when asked about the goals of civic and citizenship education are especially likely to focus on conflict reduction and activities within the school itself. How students become oriented toward political and civic participation is an important area for further study.

\section{Be Aware of Strengths and Weaknesses of Methodologies}

A methodology used in many of the studies cited above was person-centered analysis: two stage cluster analysis (Chow 2013; Wang 2019), latent profile analysis (Kuang 2016) and mixture Rasch modelling (Kuang and Kennedy 2018). The question remains as to whether similar results will be yielded by different methods. This is not only an issue for the regional studies reviewed here. Person-centered analysis of civic and citizenship data has a short history (Torney-Purta 2009) but is enjoying increasing popularity (Reichert 2016; Reichert 2017; Reichert and Torney-Purta 2019). Given the methodology's potential for revealing patterns of heterogeneity in data sets, more work is needed comparing different statistical approaches.

Missing from the ICCS studies discussed above is the use of mixed methods involving both quantitative and qualitative methods. Many studies include a suggestion that qualitative or 
mixed method studies are needed. Some attempts have been made to include a qualitative component using students of the same age as those who were surveyed within the region, usually in interviews about specific issues (Au 2013; Cheung 2016). This is a promising way to explore issues in depth to see if those raised by one sample of students resonate with another sample.

Qualitative research in these regional studies raises key issues for civic and citizenship educationthe salience of specific contexts that encourage or discourage particular attitudes and provide access to particular knowledge. A common survey provides insights into shared knowledge and attitudes and highlights differences. But explanations of differences within and across societies requires qualitative research such as interviews and focus groups. Torney-Purta et al. (2010) argued a decade ago for multi-methods approaches to research on civic engagement. Researchers should take up this challenge. A qualitative research methodology together with secondary data analysis could provide insights in this area.

\section{Explore Inter-referencing in Comparative Research Within Regions}

This chapter focused on inter-referencing as suggested by Koh (2018), dealing almost exclusively with comparisons within the region. Inter-referencing can establish what is of priority within a bounded area and in an ideological sense can preserve the integrity and independence of the area. The studies above have established the relevance and importance of citizenship research within the Asian area, highlighted commonalities and differences both within societies and across the region, and raised issues for future research. It now seems important to look beyond the region to develop a broader comparative perspective.

Some work has begun on this broader comparative agenda. As mentioned, Kuang (2016) developed a model to compare civic engagement among students in Asia, Latin America, and Europe. Reichert and Torney-Purta (2019) compared teacher profiles in societies from Asia (Taiwan, Hong Kong, and Korea) and Europe (the Czech Republic, Poland, Slovenia, Denmark, Finland, Sweden, England, Ireland, and Italy). Interpreting the results involves deep understanding of multiple societies. Optimally, such research is probably conducted by multi-national teams that have the resources to understand the distinctive contexts. As cultural psychologists have shown, these comparisons are complex because of deep seated cultural assumptions. Nevertheless, these comparisons are important and secondary analysis of ICCS data provides unique opportunities.

\section{Be Innovative in Future Regional Analyses}

As mentioned above, Wang (2019) drew her sample from two Chinese Mainland cities and used a modified form of ICCS 2009. This is promising, but the data were not gathered with the rigorous procedures used by ICCS. She went to considerable lengths to ensure that the scales used were comparable in a statistical sense and valid in a content sense since she was dealing with students in a political system that had little or no commitment to liberal democracy. Nevertheless, this is a good example of making excellent use of what ICCS has to offer.

There are also informative analyses focused on Asian data in the main survey. For example, Zhu et al. (2019) have compared native born Hong Kong students and immigrant students (born in Mainland China but going to school in Hong Kong) to understand better why immigrant students often seem to have higher civic knowledge scores than the native born. As mentioned earlier, Reichert and Torney-Purta (2019) have developed profiles of Asian teachers based on their responses to the teacher questionnaire and compared them with those of teachers in several parts of Europe. Thus, data collected from Asian students and teachers can continue to be used in useful ways comparatively. Other researchers may find it valuable to focus on inter-referencing using the Asian societies that participated in ICCS 2016 and also by examining change from ICCS 2009 to 2016. 
Finally, this chapter has raised numerous issues. The studies have shown that values can be identified that seem especially appropriate in Asian contexts. It has established that there is diversity in the endorsement of these values across the region. The results challenge the idea that "Asian" values are uniformly adopted. Specific contexts appear to influence students to endorse values differently. Many questions remain and provide a challenge for future researchers using both traditional secondary analysis of survey data and qualitative research.

The studies have shown that there are traditional values held by Asian adolescents and sometimes these are consistent with liberal democratic values (as generally defined), and sometimes they are not. An important issue is how young people balance these in their daily lives and interactions. Since 2014 we have seen radical forms of civic engagement in Asian contexts, but we do not know how such actions become reconciled with traditional values. When cultural pressures focus on obedience and harmony while societies pursue policies that are unfair and unjust, how do young people make decisions to protest the injustice? How does public discourse about radical civic action influence young adolescents whose political socialization is in process? These are important social questions, as well as significant research questions. They are questions that can be addressed by secondary data analysis to yield understanding that can benefit not only academic discourse, but the world in which we live. This presents an exciting research agenda for the future.

\section{References}

Au, W.C. (2013). The role of Hong Kong schools in promoting students' civic engagement: A mixedmethod approach. Unpublished EdD thesis, Hong Kong Institute of Education.

Baur, N. (2009). Problems of linking theory and data in historical sociology and longitudinal research. Historical Social Research, 34(1), 7-21.

Chan, W., Cattaneo, L., Mak, W., \& Lin, W. (2017). From moment to movement: Empowerment and resilience as a framework for collective action in Hong Kong. American Journal of Community Psychology, 59(1-2), 120-132.

Chen, K. S. (2005). Asia as method. Taiwan: A Radical Quarterly in Social Studies, 57, 139-218.

Cheung, H.W. (2016). The influence of attitudes to religion on civic and social values: A comparison of Hong Kong and Taiwanese students. Unpublished PhD thesis, Hong Kong Institute of Education.

Chow, K.F. (2013). The 'civic potential' of students: An investigation of students' civic knowledge and conceptions of active citizenship in five Asian societies. Unpublished PhD thesis, Hong Kong Institute of Education.

Fraillon, J., Schulz, W., \& Ainley, J. (2011). Orientations to civics and citizenship across the East Asian region. Commentary paper prepared for the Annual Meeting of the American Educational Research Association, New Orleans, 8-12 April.

Fraillon, J., Schulz, W., \& Ainley, J. (2012). ICCS 2009 Asian report. Civic knowledge and attitudes among lower-secondary students in five Asian countries. Amsterdam, the Netherlands: International Association for the Evaluation of Educational Achievement (IEA).

Guo, Z. (2014). Translating Chinese citizenship. In E. Isin, \& P. Nyers (Eds.), Routledge handbook on global citizenship studies (pp. 366-375). New York, NY: Routledge.

Hakim, C. (2013). Secondary analysis and the relationship between official and academic social research. In J. Goodwin (Ed.), SAGE secondary data analysis (pp. 27-44). London, United Kingdom: SAGE Publications. Inglehart, R., \& Baker, W. (2000). Modernization, cultural change and the persistence of traditional values. American Sociological Review, 65(1), 19-51.

Kennedy, K. (2004). Searching for citizenship values in an uncertain world. In D. Grossman, W.O. Lee, \& K. Kennedy (Eds.), Citizenship education in Asia - Concepts and issues (pp. 9-24). Hong Kong: Comparative Education Research Centre/Kluwer Academic Publishers.

Kennedy K. (2011). Is there an Asian perspective on citizenship? Learning from the International Civic and Citizenship Education Project. Keynote Address, International Citized Conference, Emory University, Atlanta, GA, 12-15 May. https://www.academia.edu/1687988/Is_there_an_Asian_Perspective_on_ Citizenship_Learning_from_the_International_Civic_and_Citizenship_Project 
Kennedy, K., Kuang, X., \& Chow, J.K.F. (2013). Exploring Asian students' citizenship values and their relationship to civic knowledge and school participation. Educational Psychology, 33(3), 240-261.

Knowles, R. (2015). Asian values and democratic citizenship: Exploring attitudes among South Korean eighth graders using data from the ICCS Asian Regional Module. Asia Pacific Journal of Education, 35(2), 191-212.

Koh, A. (2018). "Inter-referencing" as methodology: The "emotional contagion" of PISA and the discursive formation of an emergent East Asian policy field. In K. Kennedy, \& J.C.K. Lee (Eds.), Routledge international handbook of schools and schooling in Asia (pp. 40-57). New York, NY: Routledge.

Kuang, X. (2016). Alienated and disaffected students: The civic capacity of 'Outsiders' in cross cultural contexts. Unpublished PhD dissertation, The Education University of Hong Kong.

Kuang, X., \& Kennedy K. (2014). Asian students' perceptions of 'good' citizenship: The role of democratic values and attitudes to traditional culture. Asia Pacific Journal of Educational Development, 3(1), 33-42.

Kuang, X., \& Kennedy, K. (2018). Hong Kong adolescents' future civic engagement: Do protest activities count? Compare: A Journal of Comparative and International Education, 50(3), 428-446.

Lee, W.O. (2004a). Emerging concepts of citizenship in Asian contexts. In D. Grossman, W.O. Lee, \& K. Kennedy (Eds.), Citizenship education in Asia - Concepts and issues (pp. 25-35). Hong Kong: Comparative Education Research Centre/Kluwer Academic Publishers.

Lee, W.O. (2004b). Concepts and issues of Asian citizenship: Spirituality, harmony and individuality. In D. Grossman, W.O. Lee, \& K. Kennedy (Eds.), Citizenship education in Asia - Concepts and issues (pp. 277-288). Hong Kong: Comparative Education Research Centre/Kluwer Academic Publishers.

Li, L.J., Huang, X., \& Kennedy K. (2016). "Birds of a feather get together": Hong Kong and Taiwanese adolescents' aspirations for illegal protest. Paper presented at the Annual Meeting of the Comparative Education Society of Hong Kong, April 15-16. https://www.researchgate.net/publication/330089789 Birds_of_a_Feather_Get_Together_Hong_Kong_and_Taiwanese_Adolescents'_Aspirations_for_Illegal_ Protest

Li, M. (2015). Citizenship education and migrant youth in China: Pathways to the urban underclass. New York, NY: Routledge

Lin, F-L., \& Liu, M.H. (2011). International Civic and Citizenship Education Study (ICCS, 2009) - Asian regional module. Paper presented at the 52nd General Assembly of the International Association for the Evaluation of Educational Achievement, Dublin.

Lyotard, J. (1984). The postmodern condition: A report on knowledge. Minneapolis, MN: University of Minnesota.

Reichert, F. (2016). Students' perceptions of good citizenship: A person-centred approach. Social Psychology of Education, 19(3), 661-693.

Reichert, F. (2017). Young adults' conceptions of 'good' citizenship behaviours: A latent class analysis. Journal of Civil Society, 13(1), 90-110.

Reichert, F., \& Torney-Purta, J. (2019). A cross-national comparison of teachers' beliefs about the aims of civic education in 12 countries: A person-centered analysis. Teaching and Teacher Education, 77, 112-125.

Schulz, W., Ainley, J., Fraillon, J., Kerr, D., \& Losito, B. (2010). ICCS 2009 international report: Civic knowledge, attitudes, and engagement among lower-secondary school students in 38 countries. Amsterdam, the Netherlands: International Association for the Evaluation of Educational Achievement (IEA).

Shin, D.C. (2012). Confucianism and democratization. New York, NY: Cambridge University Press.

Smith, E. (2008). The use of secondary data analysis in educational research. British Journal of Educational Studies, 56(3), 323-339.

Stasiulis, D. (2004). Hybrid citizenship and what's left. Citizenship Studies, 8(3), 295-303.

Torney-Purta, J. (2009). International psychological research that matters for policy and practice. American Psychologist, 64(8), 822-37.

Torney-Purta, J., Amadeo, J., \& Andolina, M. (2010). A conceptual framework and multimethod approach for research on political socialization and civic engagement. In L. R. Sherrod, J. Torney-Purta, \& C. A. Flanagan (Eds.), Handbook of research on civic engagement in youth (pp. 497-523). Hoboken, NJ: Wiley.

Tu, W.M. (Ed). (1996). Confucian traditions in East Asian modernity. Cambridge, MA: Harvard University Press. Tu, W.M. (2000). Implications of the rise of "Confucian" East Asia. Daedalus, 129(1),195-218.

Wang, Y.P. (2019). A comparative study of Mainland and Hong Kong students' political trust, efficacy and participation. Unpublished MPhil thesis, The Education University of Hong Kong. 
Westheimer, J., \& Kahn, J. (2004). Educating the "good" citizen: Political choices and pedagogical goals. PS Political Science and Politics, 37(2), 241-247.

Zhu, J., Kuang, X., Kennedy, K., \& Mok, M. M. C. (2018). Previous civic experience and Asian adolescents' expected participation in legal protest: Mediating role of self-efficacy and interest. Asia Pacific Journal of Education, 38(3), 414-431.

Zhu, J., Kennedy, K., Mok, M.M.C., \& Halse, C. (2019). Chinese immigrant students in Hong Kong: Exploring performance and influences on their civic learning. PsyCH Journalt, 8(4), 465-476.

Open Access This chapter is licensed under the terms of the Creative Commons Attribution-NonCommercial 4.0 International License (http://creativecommons.org/licenses/by-nc/4.0/), which permits any noncommercial use, sharing, adaptation, distribution and reproduction in any medium or format, as long as you give appropriate credit to the original author(s) and the source, provide a link to the Creative Commons license and indicate if changes were made.

The images or other third party material in this chapter are included in the chapter's Creative Commons license, unless indicated otherwise in a credit line to the material. If material is not included in the chapter's Creative Commons license and your intended use is not permitted by statutory regulation or exceeds the permitted use, you will need to obtain permission directly from the copyright holder. 